\title{
THE METABOLISM OF ALDOSTERONE IN NORMAL SUBJECTS AND IN PATIENTS WITH HEPATIC CIRRHOSIS *
}

\author{
By W. S. COPPAGE, JR., D. P. ISLAND, A. E. COONER AND GRANT W. LIDDLE \\ (From the Department of Medicine, Vanderbilt University School of Medicine, \\ Nashville, Tenn.) \\ (Submitted for publication February 12, 1962; accepted May 3, 1962)
}

The importance of the liver in the metabolism of cortisol has been amply demonstrated (1-3). There is comparatively little published information, however, on the role of the liver in the metabolism of aldosterone, the most important mineralocorticoid secreted by the adrenal cortex. Chart, Gordon, Helmer and LeSher (4) have demonstrated rapid inactivation of aldosterone by liver slices and impairment of this process under anaerobic conditions. Yates, Urquhart and Herbst (5) demonstrated impairment of enzymatic inactivation of aldosterone by the passively congested rat liver. Ayers, Davis, Liebermann and Carpenter (6) demonstrated that the disappearance of tritiated aldosterone from the plasma was delayed in dogs with passively congested livers. After hepatectomy the disappearance of aldosterone from the circulation was delayed still more.

An investigation of aldosterone metabolism necessarily entails the identification and quantitation of the metabolic end products which are excreted in the urine. Very little aldosterone appears in the urine in unaltered form. The major portion of what is commonly called "urinary aldosterone" is actually a water-soluble, biologically inactive metabolite which can be reconverted to aldosterone by acidification of the urine to $\mathrm{pH} 1$. This acidhydrolyzable metabolite is frequently referred to as a "3-oxo-conjugate" of aldosterone, although its exact chemical identity is not yet known. A number of studies have shown that patients with hepatic cirrhosis and ascites have abnormally large quantities of the 3-oxo-conjugate of aldosterone in their urine $(7,8)$. This is generally considered to be a reflection of the increased secretion of aldosterone in this disorder. The major urinary metabolite of aldosterone is the ring- $\mathrm{A}$ reduction product identified as $3 \alpha, 11 \beta, 21$-trihydroxy-20-

\footnotetext{
* These studies were supported in part by grants-in-aid from the United States Public Health Service (A-1748, 2A-5092, and OG-2).
}

keto- $5 \beta$-pregnane-18-al, or tetrahydroaldosterone, by Ulick, Kusch and August (9). Earlier work had suggested a somewhat different tentative structure for which the term tetrahydroaldosterone was less applicable (10). Tetrahydroaldosterone is biologically inactive. It is apparently excreted as a glucuronic acid conjugate, inasmuch as it cannot be extracted from the urine with organic solvents until incubated with $\beta$-glucuronidase. It is usually excreted in increased quantities by patients with cirrhosis and ascites (11). Because it is derived solely from aldosterone, it has been utilized in a procedure for the indirect determination of aldosterone secretion rate. Secretion rates as determined by this method have been found to be elevated in patients with cirrhosis and ascites (11). There is a considerable body of evidence, therefore, indicating that the secretion of aldosterone and the excretion of aldosterone metabolites are elevated in patients with cirrhosis and ascites. In addition, Hurter and Nabarro (12) have recently called attention to a possible alteration in the ratio of 3-oxo-conjugate to tetrahydroaldosterone in the urine of such patients.

The quantitative role of the human liver in the metabolism of aldosterone has not, however, received adequate study. The availability of tritiated $d$-aldosterone (the natural isomer) of high specific activity has made it possible to carry out studies of aldosterone metabolism in man with advantages in identification, isolation, and quantitation afforded by the radioactive label. The present study was undertaken to elucidate the role of the normal and diseased liver in aldosterone metabolism in man. The metabolism of aldosterone administered orally was compared with that administered intravenously. Plasma aldosterone disappearance curves, patterns of urinary aldosterone metabolites, and aldosterone secretion rates were determined in normal subjects and in patients with hepatic cirrhosis. 


\section{MATERIALS AND METHODS}

Sixteen normal subjects and 9 patients with cirrhosis were studied. The normal subjects were young, healthy volunteers from the medical or technical staffs of Vanderbilt University Hospital. All of the patients with cirrhosis had gross clinical evidence of hepatic decompensation, and most of them had ascites. Derangement of hepatocellular function was confirmed in all by the usual liver function tests (sulfobromophthalein retention, serum bilirubin, cephalin flocculation, thymol turbidity, serum alkaline phosphatase, and serum proteins). In five patients histological confirmation of the diagnosis was obtained. Most of the studies were carried out on a metabolic ward, but occasionally patients were studied on the general medical wards. Complete 24-hour urine collections were made in refrigerated containers without additional preservative and were checked for completeness by urinary creatinine determinations.

$7-\mathrm{H}^{3}-d$-aldosterone, $20 \mu \mathrm{c}$ per $\mu \mathrm{g}$, was obtained from the Endocrinology Study Section, National Institutes of Health, and repurified by chromatography before use. A standard sterile stock solution, $2 \mu \mathrm{c}$ per $\mathrm{ml}$, in absolute ethanol was maintained at $-10^{\circ} \mathrm{C}$ for up to 4 weeks without significant degradation.

Determination of plasma disappearance rates. Plasma disappearance of $7-\mathrm{H}^{3}-d$-aldosterone was determined at the beginning of the metabolic day ( 8 a.m.) with patients in the fasting state. One to $4 \mu \mathrm{c}$ of the stock solution of the labeled hormone was injected through the rubber tubing of a $100-\mathrm{ml}$ infusion of 5 per cent dextrose in water into an antecubital vein. Blood samples were obtained from the opposite arm at frequent intervals for 2 hours after the injection. The total amount of blood removed from any subject did not exceed $80 \mathrm{ml}$. Plasma was separated by centrifugation and frozen at $-10^{\circ} \mathrm{C}$ until it was to be analyzed for $7-\mathrm{H}^{3}$-aldosterone. The plasma was then thawed and $45 \mu \mathrm{g}$ of unlabeled $d$-aldosterone was added to each sample to provide a basis for calculation of losses of steroid during the purification process. The plasma was extracted with dichloromethane (10 vol), and the extract was washed once with 5 per cent sodium carbonate $(1 / 10 \mathrm{vol})$, twice with distilled water $(1 / 10 \mathrm{vol})$, and taken to dryness under a stream of air. The residue was taken up in ethanol and applied to Whatman no. 2 paper and chromatographed in a system of ligroin: methanol: water $(4: 3: 1)$ and again in benzene: methanol: water $(4: 2: 1)$. Aldosterone was located by ultraviolet scanning and eluted with methanol. One-tenth of the eluate was used for the quantitation of aldosterone by means of the alkaline blue tetrazolium reaction; the figure obtained was used to calculate the recovery correction. The remainder of the eluate was counted in a Packard Tri-Carb liquid scintillation spectrometer for tritium. The tritium recovered from this procedure was considered to represent specifically $7-\mathrm{H}^{3}-d$-aldosterone, and the concentration was used in plotting the plasma disappearance curve.

Determination of urinary tetrahydroaldosterone and aldosterone secretion rate. One to $3 \mu \mathrm{c}$ of $7-\mathrm{H}^{3}-d$-aldos- terone, $20 \mu \mathrm{c}$ per $\mu \mathrm{g}$, in ethanol was injected into an antecubital vein at the beginning of the metabolic day ( 8 a.m.). Urine was then collected on ice for the ensuing 24 hours. An aliquot of the urine representing $1 / 10$ to $1 / 6$ total volume was extracted with dichloromethane and hydrolyzed at $\mathrm{pH} 6.2,40^{\circ} \mathrm{C}$ with $75 \mathrm{U}$ per $\mathrm{ml}$ of bacterial $\beta$-glucuronidase (Sigma) for 12 hours. Fresh enzyme was added and hydrolysis continued for another 12 hours. The urine was then extracted with 10 vol ethyl acetate, the extract was washed twice with $1 / 15$ vol $0.1 \mathrm{~N} \mathrm{NaOH}$, once with $1 / 10$ vol distilled water, once with $1 / 10$ vol 0.1 per cent acetic acid, and was then taken to dryness under reduced pressure. The residue was applied to Whatman no. 2 paper and chromatographed in the Zaffaroni formamide : ethylene chloride system at $30^{\circ} \mathrm{C}$ for 22 to 30 hours. A known quantity of $4-\mathrm{C}^{14}$-cortisol was also processed in identical fashion in order to provide a basis for calculating steroid losses during purification. The area corresponding to tetrahydroaldosterone $\left(R_{\text {cort isol }}=0.78\right)$ was eluted with methanol. The methanol and formamide were evaporated under reduced pressure at $40^{\circ} \mathrm{C}$ and the residue dried over calcium chloride in vacuo overnight. Acetylation was then carried out with $0.15 \mathrm{ml}$ acetic anhydride in $0.30 \mathrm{ml}$ pyridine at $30^{\circ} \mathrm{C}$ for 24 hours. The acetylation was stopped with ethanol-toluene, the solvents evaporated under reduced pressure, and then the residue was applied to Whatman no. 1 paper together with known quantities of desoxycorticosterone acetate (DCA). Chromatography was then carried out in the system heptane: methanol: water $(4: 3: 1)$ at $30^{\circ} \mathrm{C}$ for 7 to 9 hours. The area corresponding to the triacetate of tetrahydroaldosterone $\left(R_{D C A}=1.07\right)$ was eluted. The recovery of DCA indicator was used to correct for losses. Aliquots were then taken for tritium counting in a well-type liquid scintillation counter and for quantitation by alkaline blue tetrazolium reaction with DCA as standard. Secretion rate was calculated by dividing radioactivity injected by the specific activity of the tetrahydroaldosterone (11). Because indicators were used for correction of losses in each step, the total urinary tetrahydroaldosterone could be calculated.

Determination of unaltered ("free") urinary aldosterone and the 3-oxo-conjugate. Unaltered (free) aldosterone was determined on a dichloromethane extract of urine which had been adjusted to $\mathrm{pH}$ 6.0. Aldosterone released from the 3-oxo-conjugate was determined on a dichloromethane extract of urine which had been adjusted to $\mathrm{pH} 1.0$ for 24 hours before extraction by a method derived from that of Kliman and Peterson (13).

After washing twice with a $1 / 15$ vol of sodium carbonate, then once with a $1 / 10 \mathrm{vol}$ of distilled water, and finally with a $1 / 10$ vol of 0.1 per cent acetic acid, the dichloromethane was removed under reduced pressure and the residue applied to Whatman no. 2 paper. Chromatography was carried out in the system benzene: methanol: water $(4: 2: 1)$ at $30^{\circ} \mathrm{C}$ for 7 to 9 hours. $4-\mathrm{C}^{14}$-cortisol was used an an indicator to determine recovery. The area corresponding to aldosterone was eluted $\left(R_{\text {cort } 1 \text { sol } 1}=\right.$ 1.4). The eluate was dried and the residue stored over calcium chloride in vacuo overnight. Acetylation was carried out using $0.15 \mathrm{ml}$ acetic anhydride in $0.30 \mathrm{ml}$ py- 


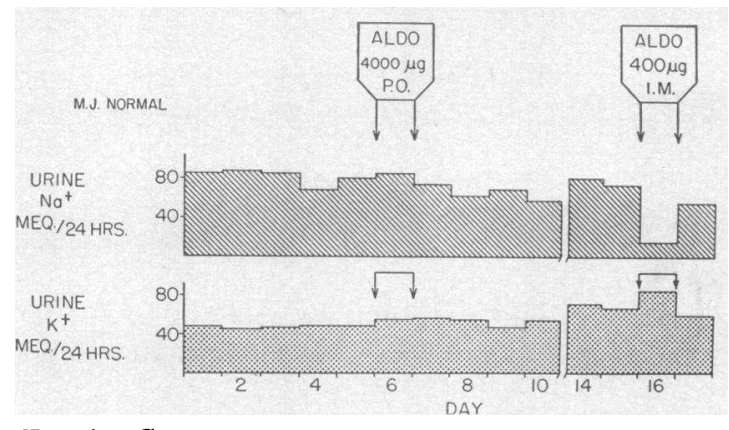

Fig. 1. Comparison OF EFFECTS OF ORAL AND INTRAMUSCULAR ADMINISTRATION OF $d$-ALDOSTERONE IN A NORMAL SUBJECT. $d$-Aldosterone, $4,000 \mu \mathrm{g}$, given orally to this subject on constant metabolic diet failed to modify urinary electrolyte excretion, whereas $400 \mu \mathrm{g}$ intramuscularly caused a significant decrease in urinary sodium and increase in urinary potassium.

ridine at $30^{\circ} \mathrm{C}$ for 24 hours. The acetylation was stopped with ethanol-toluene. Aldosterone- $\mathrm{C}^{14}$-diacetate, equivalent to approximately $2,000 \mathrm{cpm}$, was added for the determination of recovery in the remainder of the procedure. The ethanol-toluene was removed under reduced pressure and the residue applied to paper. Chromatography was carried out in the system cyclohexane: benezene: methanol : water $(4: 2: 4: 1)$ for 10 hours (aldosterone diacetate $\left.\mathrm{R}_{\mathrm{adrenosterone}}=1.0\right)$ and iso-octane: tertiary butanol: methanol: water $(12: 5: 3: 2)$ for 28 hours (aldosterone diacetate $\left.R_{11-d e s o x y c o r t 1 s o 1}=0.98\right)$. The aldosterone diacetate was eluted and dried. Oxidation was carried out with $0.2 \mathrm{ml} 0.25$ per cent chromic trioxide in glacial acetic acid for 5 to 6 minutes. The reaction was stopped with 15 per cent ethanol and the resulting solution was extracted with dichloromethane. The extract was dried under a stream of air and applied to paper. Chromatography was carried out in the system cyclohexane:benzene: methanol: water $(4: 2: 4: 1)$ for 12 hours at $30^{\circ} \mathrm{C}$. The area corresponding to the monoacetate of the oxidation product $\left(R_{11-k e t o-17 \alpha-\text { hydroxyprogester one }}=0.98\right)$ was eluted, dried, and counted for tritium and $\mathrm{C}^{14}$ in a Tri-Carb liquid scintillation spectrometer. The recovery of $4-\mathrm{C}^{14}$-cortisol in the first chromatography and the recovery of aldosterone- $\mathrm{C}^{\mathbf{1 4}}$-diacetate in subsequent steps were used to correct for losses. Unlabeled aldosterone present in the unaltered (free) and 3-oxo-conjugate fraction was then calculated from percentage of tritium recovered in each fraction and the previously determined 24-hour aldosterone secretion rate.

Urinary sodium and potassium were determined by flame photometry. Urinary creatinine was determined by the method of Folin as described by Hawk, Oser and Summerson (14).

\section{RESULTS}

Comparison of oral versus parenteral administration of $d$-aldosterone

In order to assess the quantitative role of the human liver in the metabolism of aldosterone, the steroid was administered orally to several subjects and both the metabolic effectiveness and the metabolic fate of the steroid were studied. When administered orally in dosage up to $4,000 \mu \mathrm{g}$, aldosterone had no effect upon electrolyte excretion in a subject with normal liver function. When administered intramuscularly, however, the steroid had an obvious sodium-retaining and potassiumlosing effect when given in dosage of only $400 \mu \mathrm{g}$ per day (Figure 1).

Theoretically, the ineffectiveness of orally administered aldosterone could be due either to poor absorption from the gastrointestinal tract or to virtually complete inactivation of the hormone during its initial passage through the liver. A series of studies was, therefore, performed in which $7-\mathrm{H}^{3}-d$-aldosterone was administered orally. $\mathrm{Ab}$ sorption from the gastrointestinal tract was rapid and complete, as indicated by the appearance of tritium-labeled tetrahydroaldosterone and 3-oxoconjugate in the urine in quantities comparable to those observed after the intravenous administration of $7-\mathrm{H}^{3}$ - $d$-aldosterone (Table I). After oral administration of $7-\mathrm{H}^{3}-d$-aldosterone to a normal subject, M.J., 46 per cent of the labeled steroid appeared in the urine within 24 hours as tetrahydroaldosterone, whereas after intravenous administration, 44 per cent of the labeled steroid was excreted in this form. After oral administration of the labeled hormone, 6 per cent appeared in the urine as 3-oxo-conjugate, whereas after intravenous administration, 9 per cent of the label was excreted in this form. After oral administration of $23 \mu \mathrm{c}$ of $7-\mathrm{H}^{3}-d$-aldosterone, none of the radioactivity could be detected in the blood at 30,60 , or 90 minutes, nor in the urine as unaltered aldosterone. After intravenous administration, even though only onetenth the dosage was used, the unaltered labeled hormone could be measured in the blood for 2 hours after the injection and 0.17 per cent of the administered radioactivity was recovered from the urine as unaltered aldosterone. Similar observations were made in a second normal subject, R.S. It would appear, therefore, that in subjects with normal liver function virtually no aldosterone reaches the general circulation after oral administration without having undergone metabolic alteration.

The possibility that aldosterone might be metabolized to a major extent by gastrointestinal con- 
TABLE I

Comparison of plasma concentrations and urinary derivatives of $7-H^{3}$-d-aldosterone after intravenous and oral administration to normal subjects and to a patient with a portacaval shunt

\begin{tabular}{|c|c|c|c|c|}
\hline \multirow[b]{2}{*}{ Subjects } & \multirow[b]{2}{*}{$\begin{array}{l}\text { Per cent dose in plasma as } \\
\text { unaltered aldosterone }\end{array}$} & \multicolumn{3}{|c|}{ Per cent dose in urine within $24 \mathrm{hrs}$} \\
\hline & & "Free" & $\begin{array}{l}\text { "3-Oxo-", } \\
\text { conjugate" }\end{array}$ & $\begin{array}{l}\text { Tetrahydro- } \\
\text { aldosterone }\end{array}$ \\
\hline \multicolumn{5}{|l|}{ M.J., normal female: } \\
\hline \multirow[t]{2}{*}{$\begin{array}{l}\text { Intravenous } \\
\text { Oral }\end{array}$} & $30 \mathrm{~min}$, not detectable & 0.17 & 8.7 & 44 \\
\hline & $\begin{array}{l}60 \mathrm{~min} \text {, not detectable } \\
90 \mathrm{~min} \text {, not detectable }\end{array}$ & 0.00 & 5.6 & 46 \\
\hline \multicolumn{5}{|l|}{ R.S., normal male: } \\
\hline \multirow[t]{2}{*}{$\begin{array}{l}\text { Intravenous } \\
\text { Oral }\end{array}$} & $30 \mathrm{~min}$, not detectable & 0.14 & 9.8 & 47 \\
\hline & $\begin{array}{l}60 \mathrm{~min} \text {, not detectable } \\
90 \mathrm{~min} \text {, not detectable }\end{array}$ & 0.00 & 6.4 & 36 \\
\hline \multicolumn{5}{|l|}{$\begin{array}{l}\text { L.M., postnecrotic cirrhosis, } \\
\text { portacaval shunt: }\end{array}$} \\
\hline \multirow[t]{2}{*}{$\begin{array}{l}\text { Intravenous } \\
\text { Oral }\end{array}$} & $\begin{array}{l}20 \text { min, } 2.1 \\
19 \min , 2.1\end{array}$ & 0.13 & 13 & 23 \\
\hline & $\begin{array}{l}41 \mathrm{~min}, 2.2 \\
65 \mathrm{~min}, 1.6\end{array}$ & 0.24 & 18 & 22 \\
\hline
\end{tabular}

tents or tissues rather than by the liver was excluded in the following study. $7-\mathrm{H}^{3}-d$-aldosterone was administered orally to a patient with cirrhosis who had previously undergone a portacaval anasto- mosis. Because of this anatomical arrangement, a portion of the aldosterone absorbed from the gastrointestinal tract bypassed the liver and went directly into the systemic circulation. The labeled

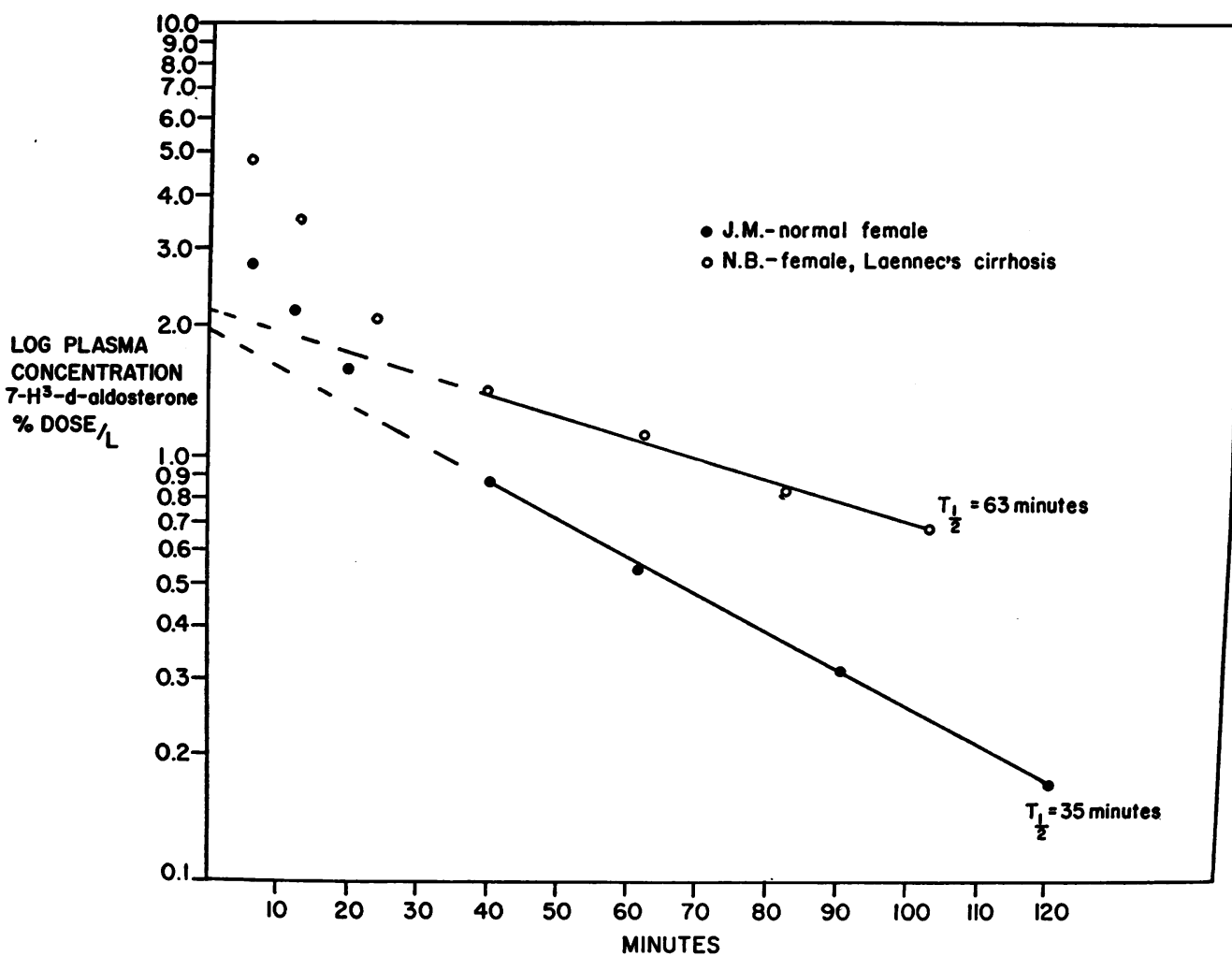

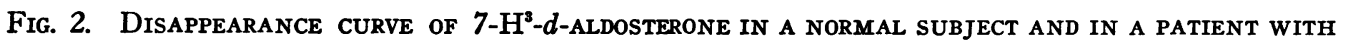
LAENNEC'S CIRRHOSIS. 
hormone was readily detectable in unaltered form in peripheral venous blood 19, 41, and 65 minutes after oral administration; 0.24 per cent of the administered dose also appeared in the urine as unaltered $7-\mathrm{H}^{3}$ - $d$-aldosterone (Table I). Oral administration of aldosterone to this patient, therefore, simulated intravenous injection of the hormone.

One may reasonably conclude from these results that there is virtually complete metabolism of aldosterone to biologically inactive products during a single passage through the normal liver.

\section{Abnormalities of aldosterone metabolism in pa- tients with hepatic cirrhosis}

Disappearance of 7- $\mathrm{H}^{3}$-d-aldosterone from plasma. The intravenous administration of $7-\mathrm{H}^{3}$ $d$-aldosterone to normal subjects immediately produced a peak concentration of the labeled hormone in the plasma. During the ensuing 30-minute period the plasma concentration fell rapidly. Then, from 30 to 120 minutes after the injection, the labeled hormone disappeared more slowly from the plasma at such a rate that the logarithm of the concentration was a rectilinear function of time (Figure 2). The slope of the latter line was employed to define the rate of disappearance of the steroid from plasma, expressed as the half-time $\left(t_{1}\right)$ of circulating aldosterone. In seven normal subjects the $t_{1}$ of circulating aldosterone so determined ranged from 26 to 39 minutes with a mean $t_{1}$ of 34 minutes (Table II).

In contrast, when $7-\mathrm{H}^{3}-d$-aldosterone was administered to six patients with hepatic cirrhosis, the plasma $t_{1}$ of the labeled steroid was prolonged, ranging from 43 to 81 minutes with a mean of 63 minutes (Figure 2, Table II). There was no overlap between the values obtained in normal subjects and those obtained in patients with cirrhosis.

In the interpretation of the aldosterone disappearance curve in patients with fluid accumulation, one must consider the possibility that the labeled hormone might have been sequestered in the ascitic fluid during mixing, and might then have re-entered the plasma at a rate sufficient to cause an apparent delay in plasma disappearance. That such was not the case, however, is indicated by the fact that the two patients with cirrhosis but without detectable ascites, Patients L.M. and N.B., also had prolonged aldosterone disappearance times. It would appear, therefore, that the prolonged half-time of circulating aldosterone in cirrhotic patients is due to liver disease per se and not to fluid retention.

Urinary excretion of 7- $H^{3}$-d-aldosterone metabolites. Three urinary excretion products of aldosterone were isolated: 1 ) the free fraction or unaltered aldosterone, 2) the so-called 3-oxo-conjugate, and 3) tetrahydroaldosterone.

After the intravenous administration of $7-\mathrm{H}^{3}-d-$ aldosterone, only a minute fraction of the labeled steroid was found as unaltered aldosterone in the urine of normal or cirrhotic subjects (Table II). In two normal subjects on liberal sodium intake, 0.14 and 0.17 per cent of the dose was recovered as unaltered hormone. One normal subject on low sodium diet excreted 0.14 per cent in this form. The unaltered fraction in seven patients with cirrhosis was slightly higher and ranged from 0.08 to 0.8 per cent of the injected dose with a mean of 0.25 per cent.

There was a clear difference between normal subjects and patients with hepatic cirrhosis in the amount of the labeled steroid excreted as the 3-oxoconjugate and as tetrahydroaldosterone (Figure 3 ). Whereas 16 normal subjects excreted, on the average, 8.9 per cent of the administered dose as the 3-oxo-conjugate, the 9 cirrhotic patients excreted 15.8 per cent of the labeled hormone in this form. On the other hand, the normal subjects excreted, on the average, 41 per cent of the dose as tetrahydroaldosterone, whereas the patients with cirrhosis excreted only 29 per cent in this form.

The rate of aldosterone secretion. The rate of secretion of aldosterone, as calculated from the specific activity of urinary tetrahydroaldosterone, was determined for normal subjects on a liberal sodium intake, for normal subjects on restricted sodium diets, and for patients with hepatic cirrhosis (Table II). In 15 normal subjects on an unrestricted diet, aldosterone secretion rate ranged from 95 to $249 \mu \mathrm{g}$ per day. In 4 normal subjects on a low sodium diet, the aldosterone secretion rate ranged from 284 to $528 \mu \mathrm{g}$ per day. Ten determinations of aldosterone secretion rate in 9 cirrhotic patients yielded values ranging from 248 to $2,080 \mu \mathrm{g}$ per 24 hours. The high rate of aldoster- 


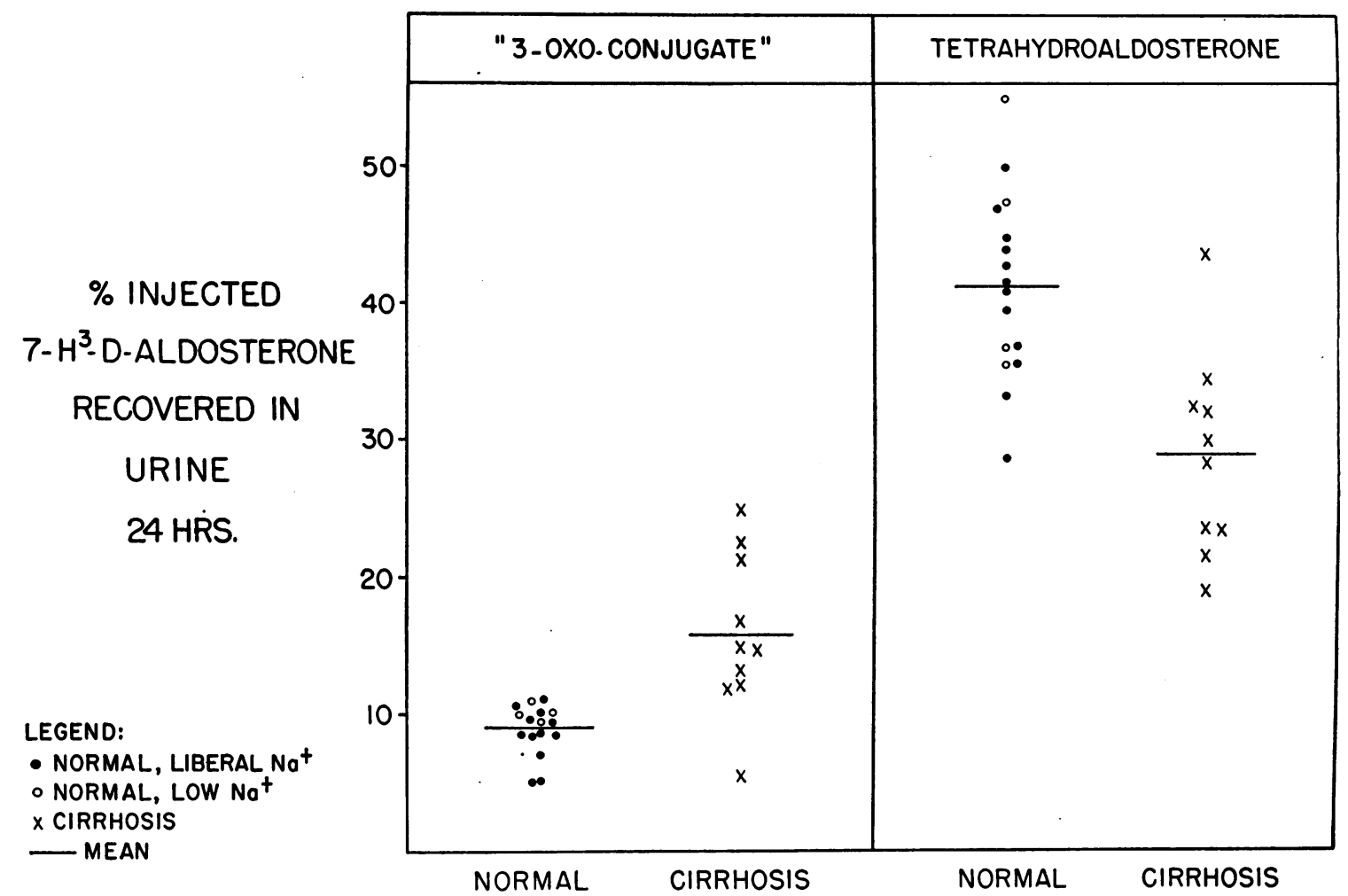

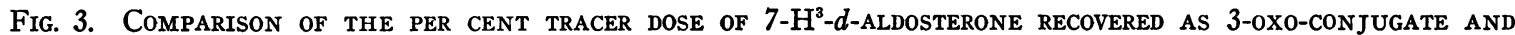
AS TETRAHYDROALDOSTERONE IN THE URINE IN 24 HOURS IN NORMAL SUBJECTS AND IN PATIENTS WITH HEPATIC CIRRHOSIS.

one secretion in the cirrhotic patients probably did not represent the effect of liver damage alone, since most of these patients were on low sodium diets at the time of study.

Since the rate of aldosterone secretion was elevated in the patients with hepatic cirrhosis, it seemed pertinent to inquire whether the rate of aldosterone secretion would itself modify the plasma disappearance of $7-\mathrm{H}^{3}-d$-aldosterone or the pattern of urinary excretion of metabolites. That an increase in aldosterone secretion rate does not of itself result in prolongation of the plasma $t_{t}$ of aldosterone becomes apparent from examination of Table II. In R.A., a normal subject whose aldosterone secretion was elevated to $528 \mu \mathrm{g}$ per 24 hours by dietary sodium restriction, the plasma $t_{1}$ of 34 minutes did not differ from those of other normal subjects with comparatively low aldosterone secretion rates. The proportion of labeled hormone excreted as the 3-oxo-conjugate or as tetrahydroaldosterone was approximately the same for the 4 normal subjects with high aldosterone secretion rates owing to dietary sodium restriction as it was for the 12 normal subjects with low aldosterone secretion rates. The delayed plasma disappearance of $7-\mathrm{H}^{3}-d$-aldosterone and the altered pattern of excretion of urinary metabolites in patients with cirrhosis, therefore, is to be attributed to the presence of hepatic disease and not to the increased rate of secretion of aldosterone.

\section{DISCUSSION}

In contrast to cortisol, which in trace amounts has a plasma $t_{1}$ of 60 to 90 minutes in normal subjects (15), aldosterone has a relatively short $t_{1}$. The average aldosterone $t_{1}$ of 34 minutes observed in the present study is almost identical with that found by Tait, Tait, Little and Laumas (16). The rate of plasma clearance of aldosterone is, like that of cortisol, slower in the presence of hepatic cirrhosis. Peterson (3) has reported a prolonged plasma $t_{1}$ of tritiated aldosterone in one of two patients with hepatic cirrhosis studied. 
The present study confirms that of Hurter and Nabarro (12) in demonstrating an increase in the 3-oxo-conjugate : tetrahydroaldosterone ratio in patients with cirrhosis. It is possible that the reduction of ring $A$ is a rate-limiting step in the metabolism of aldosterone and that this process is impaired in patients with cirrhosis. Consequently, more of the aldosterone might be metabolized to the 3-oxo-conjugate, a process which does not require ring A reduction. On the other hand, Jones and associates (17) have demonstrated a similar increase in the 3-oxo-conjugate: tetrahydroaldosterone ratio in pregnancy, a condition in which plasma aldosterone $t_{\frac{1}{2}}$ is not prolonged (18). It must be conceded, therefore, that in cirrhosis the precise relationship between the prolongation of plasma aldosterone $t_{\frac{1}{2}}$ and the shift in metabolic fate of the hormone remains speculative.

The demonstration of the relative ineffectiveness of orally administered aldosterone is in accord with the results of previous studies $(19,20)$. The use of the tritiated steroid in the present work, however, has demonstrated that the lack of effect is not due to poor absorption, since labeled metabolites quickly appear in the plasma and urine. The appearance of free aldosterone in the plasma and urine of the patient with a portacaval shunt indicates that it is the liver rather than the gastrointestinal tract which inactivates the hormone.

Both of the major metabolites of aldosterone appear to be formed in the liver, since none of the orally administered hormone escaped unaltered in its passage through the liver and since the quantities of 3-oxo-conjugate and tetrahydroaldosterone which appeared in the urine after oral administration were comparable to those observed after intravenous administration of the labeled hormone. That aldosterone is virtually all metabolized on a single passage through the normal liver, whereas cortisol is not, offers at least a partial explanation for the observation that the plasma half-time of aldosterone is considerably shorter than that of cortisol.

The high levels of urinary "aldosterone" (free plus 3-oxo-conjugate) which have been demonstrated in hepatic cirrhosis are due to three factors: increased aldosterone secretion, decreased rate of metabolism of aldosterone, and excretion of a greater proportion as the 3-oxo-conjugate, which, although inactive in itself, is converted to biologically active aldosterone by acid hydrolysis.

\section{SUMMARY}

1. The oral administration of aldosterone is ineffective in man because of rapid metabolism of the hormone during a single passage through the liver.

2. Both of the major urinary metabolites of aldosterone, 3-oxo-conjugate and tetrahydroaldosterone, are formed in the liver.

3 . The rate of removal of labeled aldosterone from the plasma is prolonged in patients with hepatic cirrhosis.

4. In hepatic cirrhosis there is an increase in the proportion of aldosterone which is metabolized to the 3-oxo-conjugate and a decrease in the proportion which is converted to tetrahydroaldosterone.

\section{REFERENCES}

1. Schneider, J. J., and Horstmann, P. M. Effects of incubating compound $\mathrm{E}$ and related steroids with various surviving rat tissues. J. biol. Chem. 1952, 196, 629.

2. Hechter, O., Frank, E., Caspi, E., and Frank, H. Corticosteroid metabolism in liver: In vivo metabolism of cortisone and cortisol by dog liver. Endocrinology 1957, 60, 705.

3. Peterson, R. E. Adrenocortical steroid metabolism and adrenal cortical function in liver disease. $\mathrm{J}$. clin. Invest. 1960, 39, 320.

4. Chart, J. J., Gordon, E. S., Helmer, P., and LeSher, M. Metabolism of salt-retaining hormone by surviving liver slices. J. clin. Invest. 1956, 35, 254.

5. Yates, F. E., Urquhart, J., and Herbst, A. L. Impairment of the enzymatic inactivation of adrenal cortical hormones following passive venous congestion of the liver. Amer. J. Physiol. 1958, 194, 65.

6. Ayers, C. R., Davis, J. O., Liebermann, F., and Carpenter, C. C. J. Effects of chronic hepatic venous congestion on the disappearance of tritiated aldosterone from plasma. Endocrine Soc. Abstr. 1960, $42,17$.

7. Axelrad, B. J., Cates, J. E., Johnson, B. B., and Luetscher, J. A., Jr. Aldosterone in urine of normal men and of patients with oedema. Its increased recovery after hydrolysis with acid and with beta-glucuronidase. Brit. med. J. 1955, 1, 196.

8. Dyrenfurth, I., Stacey, C. H., Beck, J. C., and Venning, E. $H$. Aldosterone excretion in patients with cirrhosis of the liver. Metabolism 1957, 6, 544. 
9. Ulick, S., Kusch, K., and August, J. T. Correction of the structure of a urinary metabolite of aldosterone. J. Amer. chem. Soc. 1961, 83, 4482.

10. Ulick, S., and Lieberman, S. Evidence for the occurrence of a metabolite of aldosterone in urine. J. Amer. chem. Soc. 1957, 79, 6567.

11. Ulick, S., Laragh, J. H., and Lieberman, S. The isolation of a urinary metabolite of aldosterone and its use to measure the rate of secretion of aldosterone by the adrenal cortex of man. Trans. Ass. Amer. Phycns 1958, 71, 225.

12. Hurter, R., and Nabarro, J. D. N. Aldosterone metabolism in liver disease. Acta endocr. (Kbh.) 1960, 33, 168.

13. Kliman, B., and Peterson, R. Double isotope derivative assay of aldosterone in biological extracts. J. biol. Chem. 1960, 235, 1639.

14. Hawk, P. B., Oser, B. L., and Summerson, W. H. Practical Physiological Chemistry, 12th ed. Philadelphia, Blakiston, 1947, p. 839.

15. Peterson, R. E., Wyngaarden, J. B., Guerra, S. L., Brodie, B. B., and Bunim, J. J. The physiological disposition and metabolic fate of hydrocortisone in man. J. clin. Invest. 1955, 34, 1779.
16. Tait, J. F., Tait, S. A. S., Little, B., and Laumas, K. R. The disappearance of $7-\mathrm{H}^{3}-d$-aldosterone in the plasma of normal subjects. J. clin. Invest. 1961, 40, 72.

17. Jones, K. M., Lloyd-Jones, R., Riondel, A., Tait, J. F., Tait, S. A. S., Bulbrook, R. D., and Greenwood, F. C. Aldosterone secretion and metabolism in normal men and women and in pregnancy. Acta endocr. (Kbh.) 1959, 30, 321.

18. Layne, D. S., Little, B., Meyer, C. J., Tait, J. F., and Tait, S. A. S. The turnover rate, distribution, and plasma binding of aldosterone in pregnancy. Endocr. Soc. Abstr. 1961, 43, 16.

19. Thorn, G. W., Sheppard, R. H., Morse, W. I., Reddy, W. J., Beigelman, P. M., and Renold, A. E. Comparative action of aldosterone and 9-alphafluorohydrocortisone in man. Ann. N. Y. Acad. Sci. 1955, 61, 609.

20. Ledingham, J. G. G., Martin, F. I. R., Moxham, A., Hurter, R., and Nabarro, J. D. N. The metabolic effects of aldosterone given by mouth. Lancet 1961, 1, 630. 